Open Journal of Gastroenterology and Hepatology
(ISSN:2637-4986)

\title{
Profile of Patients with Digestive Tube Cancer Infected With HIV in
} Two Cancerology Centers in Cameroon

Bekolo Nga W. T.1, $2^{*}$, Ndjitoyap Ndam A. W³, Maison Mayeh A.M ${ }^{1,2}$, Mbassi Dina Bell E ${ }^{1,2}$, Matha Mical ${ }^{4}$, Eloumou Bagnaka S.A.F. ${ }^{2,5}$, Malongue A. ${ }^{1}$, Tzeuton C. ${ }^{6}$, Noah Noah D. ${ }^{2}$, Luma H. Namme ${ }^{1,2}$, Njoya O. ${ }^{3}$, Ankouane Andoulo F. ${ }^{3}$

${ }^{1}$ Internal Medicine Department of the Douala General Hospital; ${ }^{2}$ Faculty of Medicine and Pharmaceutical Sciences of the University of Douala; ${ }^{3}$ Faculty of Medicine and Biomedical Sciences at the University of Yaoundé I; ${ }^{4}$ Faculty of Medicine of Buea; ${ }^{5}$ Internal Medicine Department of the Gyneco-Pediatric Hospital of Douala; ${ }^{6}$ Capucines clinic

\section{ABSTRACT}

Background: Human Immunodeficiency Virus (HIV) infection is a major public health problem in Africa, which alone recorded $71 \%$ of HIV / AIDS-related deaths in 2018. There is a link between the infection to HIV and the occurrence of certain cancers, in particular digestive cancers. Very little data in Africa, especially Cameroon, exists on the association between HIV and digestive cancers. Our goal was to determine the prevalence of HIV in patients with cancer of the digestive tract as well as the factors related to the prognosis of these patients in Cameroon.

Methods: We conducted a cross-sectional and analytical study over a 10-year period from January 2010 to December 2019. It was carried out in the general hospitals of the cities of Douala and Yaoundé. We included records of patients with histologically confirmed gastrointestinal cancer. We excluded records of patients with lymphoma or Kaposi's sarcoma. The data collected were socio-demographic, clinical and paraclinical data. Chisquare test was used to determine statistically significant associations for $p<0.05$.

Results: We collected 294 files, among which 71 had positive HIV serology, either a prevalence of $24.15 \%$. The average age of the patients was $53,7 \pm 13,6$ years old. The sex ratio was 1.08 . The main locations were the colon with $28.7 \%(\mathrm{~N}=20)$ and the anus with $25.4 \%(N=18)$. At the time of HIV diagnosis, the mean CD4 count at the time of HIV diagnosis was $413,2 \pm 189,3 / \mathrm{mm}^{3}$ and the ${ }^{*}$ Correspondence to Author:

Bekolo Nga Winnie Tatiana

Senior Lecturer, Faculty of Medicine and Pharmaceutical Sciences, University of Douala.

How to cite this article:

Bekolo Nga W. T., Ndjitoyap Ndam A. W, Maison Mayeh A.M, Mbassi Dina Bell E, Matha Mical, Eloumou Bagnaka S.A.F., Malongue A., Tzeuton C., Noah Noah D., Luma H.Naamme, Njoya O., Ankouane Andoulo F.. Profile of Patients with Digestive Tube Cancer Infected With HIV in Two Cancerology Centers in Cameroon. Open Journal of Gastroenterology and Hepatology, $2021 ; 4: 47$ mean viral load was $5129 \pm 2786,8$ copies $/ \mathrm{mm}^{3}$. When diagnosed with cancer, the average CD4 count was $287,84 \pm 101,7 / \mathrm{mm}^{3}$ 
and the average viral load was $25385,5 \pm 19784,3 / \mathrm{mm}^{3}$. The anal location $(p=0.003)$, the necrotic appearance $(p=0.001)$, the poorly differentiated character $(p=0.02)$ of the tumors and the death of the patients $(p=0.000)$ were statistically linked to positive HIV serology. Factors associated with the prognosis of HIV positive patients were CD4 count <200/ mm3 ( $p=0.002)$ and the existence of metastases $(p=0.04)$

\section{Conclusion:}

The prevalence of HIV in patients with cancer of the digestive tract is $24.15 \%$. The anal location, the necrotic appearance and the undifferentiated nature of the tumors are related to positive HIV serology. Prognostic factors are a CD4 count $<200 / \mathrm{mm} 3$ and the existence of metastases.

\section{Keywords: HIV; Digestive tract cancer; Prevalence; Prognostic factors}

\section{Introduction}

HIV infection is a real public health problem around the world ${ }^{[1]}$. Sub-Saharan Africa remains the most affected region, despite notable advances in terms of prevention, screening and care, with a prevalence of 25.6 million people infected and 1.280 million new cases recorded in $2018^{[1]}$. In Cameroon, the prevalence was estimated in 2018 at $3.6 \%$ or 540,000 people living with HIV, including 23,000 new cases ${ }^{[2]}$. The human immunodeficiency virus is responsible for a decline in immunity, which results in the development of opportunistic infections but also in many comorbidities, including cancers [3,4]. Some (Kaposi's sarcoma, lymphoma) are closely linked to HIV infection, others are said to be "unrelated to HIV" especially at the digestive level ${ }^{[3-5]}$. A few studies, mostly conducted in the West, have been able to assess the correlation between HIV infection and the occurrence of socalled "non-HIV" cancer [4-7]. They showed that the risk of the onset of cancer increased when the patient was put on antiretroviral treatment because it increased his life expectancy [5-7]. There is very little data in our community on socalled "non-HIV-related" cancers in patients infected with HIV. The available data mainly concern HIV-related cancers and gynecological cancers [8-10]. The aim of this study was to find the profile of patients with "non-HIV-related digestive tract cancer" in patients with HIV infection.

\section{Methodology}

We vonducted a cross-sectional and analytical study over a period of 10 years from January 1 ,
2010 to December 31, 2019. It was part of the oncology and radiotherapy services of the general hospitals of the cities of Douala and Yaoundé in Cameroon. We Included patients with HIV infection who had histologically confirmed digestive tract cancer. Patients with non-Hodgkin's malignant lymphoma or Kaposi's sarcoma and incomplete records were excluded from this work. The data collected were socio-demographic data (age, sex), past medical history (arterial hypertension, diabetes, the notion of alcohol consumption and tobacco use), clinical data (the date of onset of symptoms concerning cancer, date of consultation, clinical signs related to cancer, date of death), paraclinical data (hemoglobin level, transaminases, uremia, serum creatinine, ACE, CA 19.9, CD4 count at the time of diagnosis of HIV and cancer, HIV viral load at the time of HIV and cancer diagnosis, localization, histological type and extension workup) and treatment (surgery, chemotherapy, radiotherapy).

Data were analyzed using SPSS software. The FISCHER Chi-square test was used to compare the different variables. Logistic regression was used to determine associations between variables with a significance for a $p<0.05$. The Kaplan Meier curve was used to determine overall survival.

\section{Operational terms}

HIV positive patients: patients whose HIV serology obtained by an ELISA test is found in the file

Incomplete files: patient files where there is no histological proof of cancer, socio-demographic 
data (age and sex), clinical and paraclinical

Cancer unrelated to HIV: any histological type other than lymphoma and Kaposi's sarcoma

Symptom onset date: the date on which the first cancer-related symptoms appeared

Date of diagnosis: date the diagnosis of cancer was made

Time to diagnosis: period between the onset of symptoms and the date on which the cancer diagnosis is known

\section{Results}

Table I: General characteristics of the population

\begin{tabular}{|c|c|c|c|c|c|}
\hline $\begin{array}{l}\text { localisation } \\
\text { Variables }\end{array}$ & $\begin{array}{l}\text { All types of cancers } \\
\qquad(n=71)\end{array}$ & $\begin{array}{l}\text { Esophagus } \\
\qquad(n=7)\end{array}$ & $\begin{array}{l}\text { Stomach } \\
(n=13)\end{array}$ & $\begin{array}{l}\text { Colorectal } \\
(n=33)\end{array}$ & $\begin{array}{l}\text { Anus } \\
(n=18)\end{array}$ \\
\hline Mean age (years) & $53.7 \pm 13.6$ & $57.7 \pm 16.1$ & $57.4 \pm 14.8$ & $53.7 \pm 12.9$ & $46 \pm 10.5$ \\
\hline \multicolumn{6}{|l|}{$\operatorname{Sex} n(\%)$} \\
\hline Female & $34(47.9)$ & $2(28.6)$ & $4(30.8)$ & $12(36.4)$ & $16(88.9)$ \\
\hline Male & $37(52.1)$ & $5(71.4)$ & $9(6.2)$ & $21(63.6)$ & $2(11.1)$ \\
\hline Average time to diagnosis (months) & $10.9 \pm 15.3$ & $1.5 \pm 0.7$ & $22 \pm 24.7$ & $5.6 \pm 6.1$ & $14.6 \pm 29.6$ \\
\hline \multicolumn{6}{|l|}{ Family history (n/\%) } \\
\hline Anal cancer & $4(5.6)$ & & & & \\
\hline \multirow[t]{2}{*}{ Others cancers } & $1(1.4)$ & & & & \\
\hline & $5(7)$ & & & & \\
\hline \multicolumn{6}{|l|}{ Comorbidities (n/\%) } \\
\hline Alcohol & $13(18.3)$ & & & & \\
\hline Tobacco & $11(15.4)$ & & & & \\
\hline Hypertension & $5(7)$ & & & & \\
\hline Diabetes & $7(9.9)$ & & & & \\
\hline \multicolumn{6}{|l|}{ Average CD4 count $\left(\mathrm{c} / \mathrm{mm}^{3}\right)$} \\
\hline \multicolumn{6}{|l|}{ At HIV diagnosis } \\
\hline \multirow[t]{2}{*}{ At Cancer diagnosis } & $413.2 \pm 189.3$ & & & & \\
\hline & $287.3 \pm 101.7$ & & & & \\
\hline \multirow{2}{*}{\multicolumn{6}{|c|}{$\begin{array}{c}\text { Average viral load (copies } / \mathrm{mm}^{3} \text { ) } \\
\text { At HIV diagnosis }\end{array}$}} \\
\hline & & & & & \\
\hline \multirow[t]{2}{*}{ At cancer diagnosis } & $5129 \pm 2786,8$ & & & & \\
\hline & $25385 \pm 19784.3$ & & & & \\
\hline \multicolumn{6}{|l|}{ Evolution } \\
\hline Death & $28(39.4)$ & & & & \\
\hline Lost & $30(42.2)$ & & & & \\
\hline
\end{tabular}

Table II: Clinical presentation according to location

\begin{tabular}{lll}
\hline Location & Clinical presentation & Fréquency(\%) \\
\hline Esophagus $\mathbf{n = 7}$ & Weight loss & $5(71.4)$ \\
& Dysphagy & $4(57.1)$ \\
& Anorexia & $3(42.9)$ \\
\hline Stomach $\mathbf{n = 1 3}$ & Epigastralgia & $8(61.5)$ \\
& Anorexia & $7(53.8)$ \\
\hline Colorectal $\mathbf{n = 3 3}$ & Asthenia & $6(46.1)$ \\
& Abdominal pain & $15(45.4)$ \\
& Weight loss & $14(42.4)$ \\
Anus $\mathbf{n = 1 8}$ & Anorexia & $13(39.4)$ \\
& Anal pain & $15(83.3)$ \\
& Rectal bleeding & $10(55.6)$ \\
& Tenesmus & $5(27.7)$
\end{tabular}


Table III: Anatomo-pathological characteristics according to the location

\begin{tabular}{cccccc}
\hline $\begin{array}{c}\text { location } \\
\text { Variables }\end{array}$ & $\begin{array}{c}\text { All type of can- } \\
\text { cers }(\mathbf{n}=\mathbf{7 1})\end{array}$ & $\begin{array}{c}\text { Esophagus } \\
(\mathbf{n}=\mathbf{7})\end{array}$ & $\begin{array}{c}\text { Stomach } \\
(\mathbf{n}=\mathbf{1 3})\end{array}$ & $\begin{array}{c}\text { Colorectal } \\
(\mathbf{n}=\mathbf{3 3})\end{array}$ & $\begin{array}{c}\text { Anus } \\
(\mathbf{n}=\mathbf{1 8})\end{array}$ \\
\hline Macroscopy & & & & & \\
Ulcerative bud & $26(36.6)$ & $1(14.3)$ & $7(53.8)$ & $11(42.3)$ & $7(38.9)$ \\
Stenosing & $20((28,2)$ & $4(57.1)$ & $5(38.5)$ & $7(21.2)$ & $4(22.2)$ \\
Necrotic & $19(26.8)$ & $1(14.3)$ & $5(38.5)$ & $10(30.3)$ & $3((1.7)$ \\
Ulcerated & $15(21.1)$ & $3(42.9)$ & $4((30.8)$ & $2(6.1)$ & $6(33.3)$ \\
Budding & $9(12.8)$ & $2(28.6)$ & $3(23.1)$ & $3(9.1)$ & $1(5.6)$ \\
\hline Histology (n /\%) & & & & & \\
Adenocarcinoma & $58(81.7)$ & $4(57.1)$ & $13(100)$ & $33(100)$ & $8(44,4)$ \\
Squamous cell carcinoma & $13(18.3)$ & $3(42.9)$ & $0(0)$ & $0(0)$ & 10 \\
& & & & & $(55,6)$ \\
\hline Staging n (\%) & & & & & 15 \\
Stage I-III & $48(67.6)$ & $2(28.6)$ & $8(61.5)$ & $23(69.7)$ & 15 \\
Stage IV & $23(32.4)$ & $5(71.4)$ & $5(38.5)$ & $10(30.3)$ & $(83.3)$ \\
& & & & & $3(16.7)$ \\
\hline
\end{tabular}

Table IV: Multivariate analysis of factors linked to positive HIV serology

\begin{tabular}{ccccccc}
\hline Variables & \multicolumn{2}{c}{ HIV (+) } & \multicolumn{2}{c}{ HIV (-) } & Odds ratio (Cl95\%) & P-value \\
& $\mathrm{n}$ & $\%$ & $\mathrm{n}$ & $\%$ & & \\
Anal localization & 18 & 25.4 & 5 & 7 & $\mathbf{4 . 4 8}(\mathbf{1 . 5 6 - 1 2 . 8 7 )}$ & $\mathbf{0 . 0 0 3}$ \\
Necrotic appearance & 19 & 26.8 & 4 & 5.6 & $\mathbf{6 . 1 2}(\mathbf{1 . 9 6 - 1 9 . 0 0 9 )}$ & $\mathbf{0 . 0 0 1}$ \\
Weak differaciation & 16 & 22.5 & 6 & 8.5 & $\mathbf{3 . 1 5}(\mathbf{1 . 1 5 - 8 . 6 1 )}$ & $\mathbf{0 . 0 2}$ \\
Death & 28 & 39.4 & 7 & 9.9 & $\mathbf{5 . 9 5}(\mathbf{2 . 3 9 - 1 4 . 8 5 )}$ & $\mathbf{0 . 0 0 0}$ \\
\hline
\end{tabular}

Table V: Prognostic factors of patients

Variables

CD4 count $<200 / \mathrm{mm}^{3}$
OR

18.80
Cl $95 \%$

$2.81-125.92$
P-value

0.0025
Stage IV

We collected 556 patient files and included 294 files, which corresponds to $52.9 \%$. The prevalence of patients with HIV was $24.15 \%(n=71)$. Male patients represented $52.1 \%(n=37)$ for a sex ratio of 1.08 (Table I). The mean age of the patients was $53.7 \pm 13.6$ years, with extremes of 21 years and 80 years (Table I). The mean time to diagnosis was $10.9 \pm 15.3$ months (Table I). The main clinical signs were a function of location. These were for esophageal cancer of weight loss ( $\mathrm{n}=5$ or $71.4 \%$ ) and dysphagia $(\mathrm{n}=$ 4 or $57.1 \%$ ); for stomach cancer of epigastralgia ( $n=8$ or $61.5 \%$ ) and anorexia ( $n=7$ or $53.8 \%$ ); for colorectal cancer, abdominal pain $(n=15$ or $45.4 \%$ ) and weight loss ( $n=14$ or $42.4 \%$ ); and for anal cancer, anal pain ( $\mathrm{n}=15$ or $83.3 \%$ ) and rectal bleeding ( $n=10$ or $55.6 \%$ ) (Table $I$ ).
Biologically At the time of HIV diagnosis, the mean CD4 count was 413.2 $\pm 189.3 / \mathrm{mm} 3$ and the mean viral load was $5129 \pm 2786.8$ copies (Table I). However, at the time of cancer diagnosis, the mean CD4 count was $287.8 \pm 101.7$ / $\mathrm{mm} 3$ and the mean viral load was $25385.5 \pm$ 19784.3copies / mm3 (Table I). The main locations were the colon ( $\mathrm{n}=20$ or $28.2 \%$ ) and the anus ( $\mathrm{n}=18$ or $25.4 \%)$. It was an ulcerative budding tumor in $36.6 \%$ of patients $(n=26)$, stenosing in $28.2 \%$ of patients $(n=20)$ (Table III). The main histologic type was adenocarcinoma in $81.7 \%$ of patients $(n=58)$ (Table III). These tumors were metastatic in $32.4 \%$ of patients $(n=23)$ (Table III).

By comparing HIV positive patients to HIV negative patients, it emerged that the anal location 
$(p=0.003 ;$ OR $=4.5(1.6-12.9))$, the necrotic aspect of the tumor $(p=0.001$; OR $=6.1(1.9-19))$, weak differentiation $(p=0.02 ; O R=3.1(1.1-8.6))$ and death of patients $(p=0.000$; OR $=5.9$ (2.414.8)) were linked to positive HIV serology (Table IV).

The mortality rate was $39.4 \%(n=28)$. Overall survival was $7.4 \pm 7.1$ months (34.1 weeks) and the median survival was 5 months. Factors linked to the prognosis of HIV patients are the existence of metastases ( $p=0.04$; OR $=3.1$ (19.5)) and a CD4 count $<200 / \mathrm{mm} 3$ at the time of cancer diagnosis $(p=0.002 ;$ OR $=18.8$ (2.8125.9)) (Table V).

\section{Discussion}

One of the main biases of our study was the absence of HIV serology in many patient charts. However, we were able to determine an HIV prevalence that was 8 times higher than that found in the general population in Cameroon which was $3.6 \%$ in 2018 according to UNAIDS [2]. However, such a difference remains to be put into perspective first of all because of our sampling a large number of patients were excluded from our study. We had excluded some specific histology and many patients did not have serology on their chart. In addition, the HIV prevalence in Cameroon is estimated in a population whose age range is between 15 and 49 years, while the average age of our patients is 53.7 years. This mean age is significantly higher than that of Ebogo-Belobo et al in Cameroon for HIV positive cancer patients, who found him an average age of 36 years ${ }^{[8]}$. Such a difference is explained by the fact in the study by EbogoBelobo et al, the proportion of digestive cancer unrelated to HIV whose mean age of onset is generally greater than 50 years was only $3.77 \%$ $[8,11,12]$.

Clinically, the delay in diagnosing patients, which is also found in numerous studies in Africa [11-14], calls into question their path, particularly in oncology, most having consulted in many health centers before the diagnosis was made. raised but also on the cost of health care in Africa. The clinical presentation of the patients varied according to the location but was consistent with that found in the literature, particularly in Africa [11-14].

There is a decrease in the CD4 count although it remains above $200 / \mathrm{mm} 3$ and a marked increase in the viral load of HIV at the time of cancer diagnosis compared to that of HIV diagnosis. Thus, the occurrence of digestive cancers unrelated to HIV does not seem to be related to the patient's level of immunesuppression. The increased viral load at the time of cancer diagnosis confirms the role of viral replication in the development of cancer [15].

The most frequent location is the colon, which is the first digestive cancer in the general population [16]; but anal cancer is found in 2nd positive which is not the case in HIV negative patients. Anal cancer is very commonly found in HIV positive patients ${ }^{[4-6]}$. The main histological type is adenocarcinoma due to the colonic localization. During the extension workup, a third of the patients had a tumor disease classified stage 4, this being able to be explained by the very long delay of diagnosis of the patients.

By comparing HIV positive and HIV negative patients, we were able to see that HIV also had an impact in terms of location, histology, but also on the patient's prognosis. By acting on the P53 gene, HIV causes accelerated tumor growth, thus promoting its necrotic character but also its weak differentiation ${ }^{[15]}$. It also plays a role in patient survival, as deep immunosuppression coupled with the existence of metastases contributes to patient death.

It should be noted the large number of patients lost to follow-up, which could if the fate of these patients were known to modify overall survival. this aspect also poses the problem of follow-up in patients in Africa, particularly in oncology. the cost of care and ancillary costs often linked to patient follow-up contribute to stopping care. The average patient survival is significantly lower than that found in other studies in Cameroon, in particular those of Eloumou et al ${ }^{[12]}$ or Bekolo et al ${ }^{[11]}$. We also note a mortality rate markedly higher than that of de Ouedraogo et al in Burkina Faso ${ }^{[17]}$ but it is lower than that of Kissi Azouan-Kacou et al in Côte d'Ivoire [18]. 
These different results should be put into perspective due to the large number of patients lost to follow-up during the study period. However, the poor prognosis of the patients is probably related not only to the delay in diagnosis, the cost of treatment and follow-up in oncology, but also their serological status which contributes to the worsening of their state of health.

\section{Conclusion}

The prevalence of HIV in digestive cancer patie$n$ ts is $24.15 \%$ and is significantly higher than in the general population. The average age of patients is similar to that of HIV negative patients. there is a delay in diagnosis often common in Africa in oncology patients. A positive HIV serology has an impact on tumor location but also on the histology and the patient's future. Overall survival is 7.4 months. Factors associated with patient prognosis are CD4 count $<200 / \mathrm{mm} 3$ and tumor stage. It has also been noted that some number of patients have no HIV serology in the files.

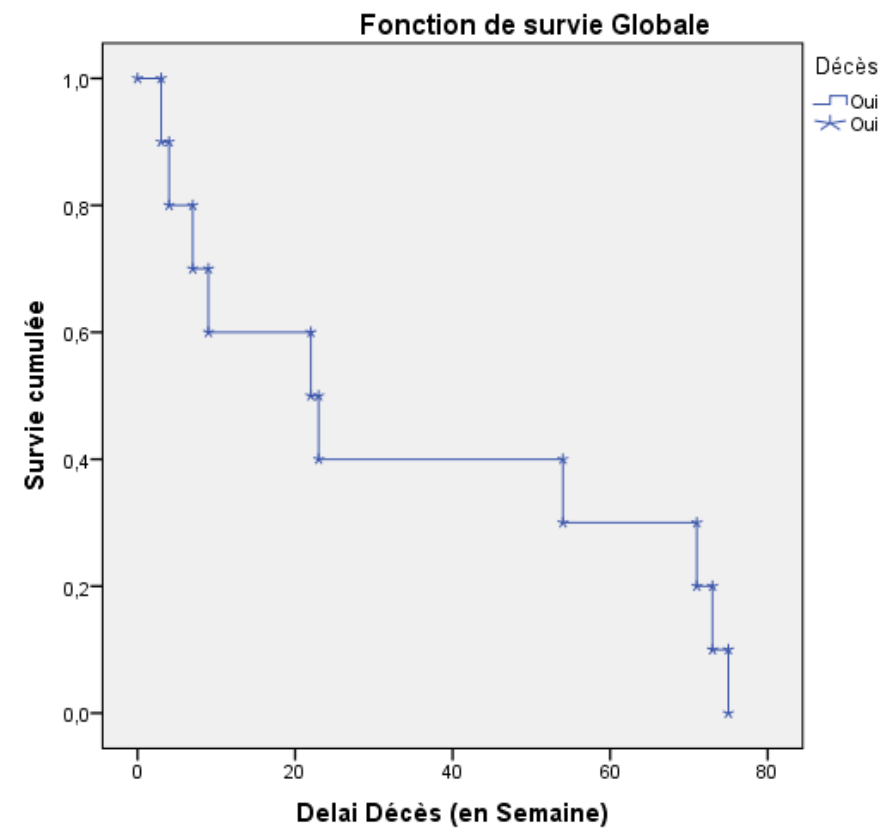

Figure 1: Overall survival

\section{Abbreviations:}

HIV: human immunodeficiency virus

Conflicts of interest: none

Design of the work: Winnie Tatiana Bekolo Nga, Servais Albert Fiacre Bagnaka Eloumou. Data collection and statistical analysis: Winnie Tatiana Bekolo Nga, Mical Matha, Anne Marthe Maison Mayeh, Esther Mbassi Dina Bell. Drafting of the draft: Winnie Tatiana Bekolo Nga, Servais Albert Fiacre Bagnaka Eloumou, Mical Matha. Correction of the draft: Servais Albert Fiacre Bagnaka Eloumou, Ankouane Andoulo Firmin, Antonin Ndjitoyap Ndam, Henry Namme Luma, Dominique Noah Noah.

\section{References}

[1] UNAIDS data 2019. Global HIV and AIDS statistics. 25th December 2018
[2] UNAIDS. Country factsheets Cameroon 2018.pdf [Internet]. Available from: https://www.unaids.org/sites/default/files/media asset/global-aids-monitoring en.pdf

[3] HIV Infection and Cancer Risk [Internet]. National Cancer Institute. 2017 [cited Nov 2019]. Available from:

https://uww.cancer.gov/about-cancer/causesprevention/risk/infectious-agents/hiv-fact-sheet

[4] Thrift AP, Chiao EY et al. Are Non-HIV Malignancies Increased in the HIV-Infected Population? Curr Infect Dis Rep. 2018 Aug;20(8):22.

[5] Clifford GM, Polesel J, et al. Cancer Risk in the Swiss HIV Cohort Study: Associations With Immunodeficiency, Smoking, and Highly Active Antiretroviral Therapy. JNCl Journal of the National Cancer Institute. 2005 Mar 16;97(6): 425-32.

[6] Nagata N, Nishijima T, et al. Increased risk of nonAIDS-defining cancers in Asian HIV-infected 
patients: a long-term cohort study. BMC Cancer. 2018 Dec;18(1):1066.

[7] Deeken J.F, Tjen-A-Looi $A$ et al. The Rising of Non AIDS-Defining Cancers in HIV infected Patients. Clin Infect Dis. 2012 Nov;55(9):1228-35.

[8] Ebogo-Belobo J-T, Kagoué Simeni L-A, et al. Incidence of cancer in people living with HIV and prognostic value of current CD4. Bull Cancer. 2019 Mar;106(3):201-5.

[9] Enow Orock G et al. Co-morbidity of HIV and Cervical Cancer: A One Year Multicentric Pilot Study in Cameroon. 2019;6.

[10] Enow Orock et al. Co Morbidity of HIV and Breast Cancer: A One Year Multicentric Pilot Study in Cameroon. (194):6.

[11]WT Bekolo, Eloumou SAFB et al. Facteurs pronostiques du cancer de l'œsophage au Cameroun: étude multicentrique. Pan Afr Med Journal. 2019; 33:73.

[12] SAF Eloumou Bagnaka, WT Bekolo Nga et al. Facteurs pronostiques du Cancer colorectal au Cameroun. Health Sciences and Diseases. 2020 ; $20(2)$.

[13] Ouedraogo S, Ouedraogo S, Kambire JL, Zoungrana SL, et al. [Epidemiological, clinical, histological, and therapeutic features of primary digestive cancers in Burkina Faso]. Bull Cancer. 2018 Dec;105(12):1119-25.

[14] Ouedraogo S, Ouedraogo S, Kambire JL, Zoungrana SL, et al. [Epidemiological, clinical, histological, and therapeutic features of primary digestive cancers in Burkina Faso]. Bull Cancer. 2018 Dec;105(12):1119-25.

[15] Lu R, Wu S, et al. HIV Infection Accelerates Gastrointestinal Tumor Outgrowth in NSG-HuPBL Mice. AIDS Research and Human Retroviruses. 2014 Jul;30(7):677-84.

[16] Bray F, Ferlay J, et al. Global cancer statistics 2018: GLOBOCAN estimates of incidence and mortality worldwide for 36 cancers in 185 countries. CA Cancer J Clin. 2018;68(6):394-424.

[17] Ouedraogo S., Ouedraogo S. et al. Profil épidémiologique, clinique, histologique, et thérapeutique des cancers digestifs primitifs dans les régions du nord et est du Burkina Faso. Bulletin du Cancer. 2018 ; 105(12) : 1119-1125.

[18] Kissi Azouan-Kacou H. Y., Doffou S.A et al. Prise en charge des cancers digestifs en Côte d'Ivoire : expérience du service d'Hépato-gastroentérologie du CHU de Youpougon. Journal africain d'Hépato-gastroentérologie. 2017 ;11:13-18. 